\title{
New perspectives on miniscrews: improving stability
}

\author{
D. Brézulier ${ }^{1}$, O. Sorel ${ }^{2}$ \\ 1 Resident, University of Rennes 1, CHU Rennes \\ 2 Professor-hospital practitioner, Head of the departement of Orthodontics, University of Rennes 1, \\ CHU Rennes
}

\section{SUMMARY}

With the appearance of bone anchorages, orthodontists thought that they would finally be able to overcome the thorny problem of patients' cooperation. The first considerations were about the safety, the holding time, and the reliability of these devices. Both theoretical and clinical studies have attempted to answer to these questions, and several studies have been published on the same. What have we learned about the reliability of miniscrews 20 years after their introduction in our daily practice? Are they only a way to solve the problem of patient noncompliance? And finally, in which way are they going to evolve? These are questions we aim to answers in the light of the past and the current literature.

\section{KEYWORDS}

Temporary anchorage device, miniscrew, orthodontics

\section{NEW PARAMETERS FOR IMPROVED STABILITY OVER TIME}

In 2002, there was considerable variability in screw design. Melsen's work has paved the way for numerous studies aimed at improving the stability of miniscrews in the short to medium term ${ }^{14-16,28}$. The latest developments are summarized below.

\section{Short-term stability}

The stability of the screws, defined as their stability over the entire duration of the active phase of treatment ${ }^{43}$, is linked to three types of parameters: screw morphology itself, the patients, and finally the practitioners.
The morphology of the screws has been a topic of discussion for approximately 10 years ${ }^{27}$. The characteristics include the following: the design and length of the threaded part, the diameter of the screw (Fig. 1), the design of the gingival neck, and the shape of the head. These technical characteristics seem to be well defined for transgingival screws implanted in the cortical bone. There are two types of screws: self-drilling and self-tapping. There was no initial difference in grip nor in shape or strength ${ }^{45,49}$, be it conical or cylindrical. There is a recommended length of $>8 \mathrm{~mm}$ at the maxilla and $6 \mathrm{~mm}$ at the mandible ${ }^{42}$; regardless of the

Address for correspondence:

Damien Brézulier

2, Avenue du Professeur Léon Bernard - 35000 Rennes - France

E-mail: damien.brezulier@univ-rennes1.fr

Article received: 21-02-2016. Accepted for publication: 30-05-2016.

This is an Open Access article distributed under the terms of the Creative Commons Attribution License (http://creativecommons.org/licenses/by/4.0), which permits unrestricted use, distribution, and reproduction in any medium, provided the original work is properly cited. 
location, approximately $3.8 \mathrm{~mm}$ must be intraosseous ${ }^{48}$.

The bone-related criteria play an important role in the short-term suc-

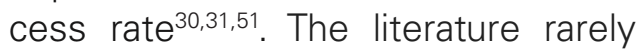
differentiates between the density of the spongy bone and the thickness of the cortex, which are two different elements. However, a 1-mm cortical thickness ensures correct primary stability $^{37}$. The density of the spongy bone is a secondary parameter ${ }^{41}$. Lastly, with regard to the installation of the screw itself, an insertion torque of 7.5 $\mathrm{N} / \mathrm{cm}$ is recommended to strengthen the grip of the screw ${ }^{29,45,48}$. Loading, whether immediate or delayed, does not affect the screw's grip. 8,27,38

\section{Medium-Term Stability}

The challenge here is to maximize the screw grip without having attained osseointegration ${ }^{13}$. Surgical screws made of steel, pure titanium, or titanium alloy-aluminum-vanadium $\mathrm{Ti}_{6} \mathrm{Al}_{4} \mathrm{~V}$ are available on the market. ${ }^{1}$ The surgical steel and the titanium alloy have mechanical properties which decrease the risk of fracturing the screw during its installation or removal. Different surface treatments have been tested and are proposed: microsandblasting, chemical etching, and mechanical machining.

Nevertheless, none of these treatments have proven to be superior in medium-term behavior in comparison with the others ${ }^{37}$. The type of orthodontic mechanisms used does not influence the stability of the screws, whether it is molar distalization by anchoring in the alveolar or palatal bone, mass recession of the arch, molar intrusion, or correction of incisal overbite by intrusion ${ }^{35,37}$. Long-term stability is also dependent on the control of inflammation and the sprouting of soft tissue

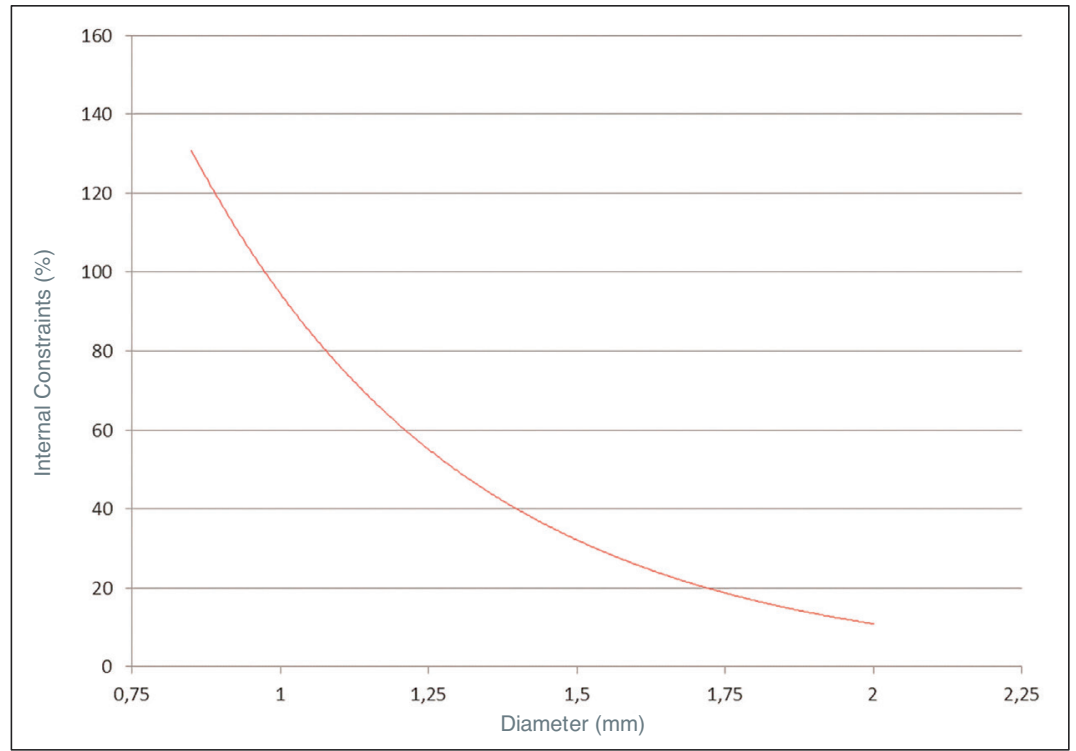

Figure 1

Diagram illustrating the relationship between the diameter and the internal force of the miniscrew. Note that the force is not inversely proportional to screw diameter. (Reproduced from Melsen B.) Skeletal anchorage indications in orthodontics. (Review of Dento-Facial Orthopedics, 2006, 40 (1): 41-61.) 
around the screw. Keratinized gingival implantation is strongly recommended in the literature $2,4,12,21,25,32,46$. However, implantation in the keratinized zone does not guarantee the absence of inflammation (Fig. 2). The implantation zone is a space bordered by the crestal apex and the mucogingival line. The placement of screws in these areas is hampered by the challenge of root morphology. Avoiding root proximities is crucial to the stability of the screws. To do this, it is possible to vary their insertion angles ${ }^{8,39}$ (Fig. 3). However, it should be noted that if a screw placed in contact with a root, only minimal damage occurs if it is quickly removed and if the cement repair is performed quickly and efficiently 3,7,18,20,22,23,40,57.

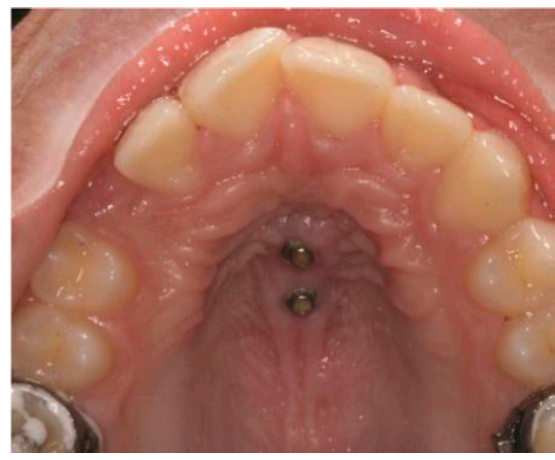

Figure 2

These palatal screws were inserted into the intermaxillary suture. Note the edematous aspect of the mucosa 1 week after placement because of the lack of hygiene in this area.
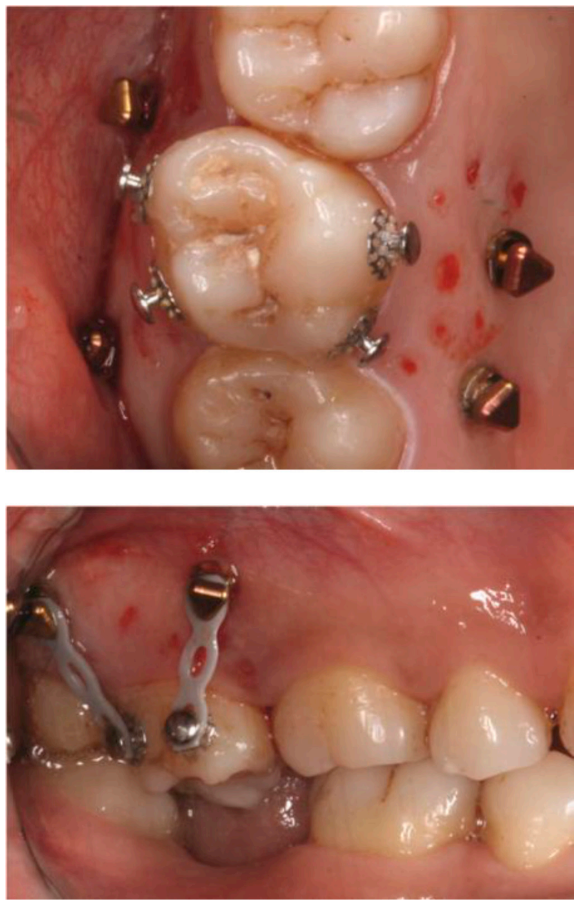

Figure 3

In this patient, four transgingival screws were placed to allow for the ingression of the second maxillary molar. Corticotomy points were created in the same session. Note the angulation of the screws relative to the cortex.

Today, the stability rate of the screws is $>92 \%$. As a result, the use of miniscrews has increased considerably in recent years. For example, a recent study shows that $62 \%$ of German orthodontists use bone anchors, $>50 \%$ of whom use them on more than two new patients per quarter ${ }^{5}$.

\section{ARE THE PATIENTS RELIEVED OF THEIR DUTY TO COOPERATE OR ARE THERE NEW RESPONSIBILITIES?}

The use of the miniscrews implies that there is no need to request the patient's cooperation in terms of wearing extraoral appliances or interarch tractions. However, these bone anchoring devices have in fact 
shifted the need for patient cooperation away from the device and toward maintaining hygiene in the area surrounding the screw.

\section{Problems with cooperation}

The success of orthodontic treatments as well as their duration are dependent on different criteria among which three are the direct responsibility of the patients: poor oral hygiene, improper wearing of the interarch elastic, and the detachment of attachments ${ }^{44}$. Patient cooperation is, therefore, a key issue for $u^{6,11,17,33}$. Most practitioners have encountered difficulties in motivating the most recalcitrant patients. Numerous patient compliance devices, e.g., in the area of upper molar distalization, have been compared ${ }^{24,34}$. Among these are the traditional pendulum, distal jet, and jig. It seems that none of the devices is devoid of confounding effects (tipping, loss of vertical control, and rotation) or undesirable effects (pushing of the pellets in the palatal mucosa, breakage of the device). The desire to avoid having to constantly solicit our patients' cooperation has cost us in terms of efficiency.

To this end, it became mandatory to develop new techniques, which were both more efficient and less dependent on patient cooperation. The contributions of bone anchor screws facilitated the implementation of treatments, which were previously deemed complicated given the extent of the cooperation required

Table I: Comparison of the devices studied or described by Melsen, Wilmes et Chillès.

\begin{tabular}{|c|c|c|c|}
\hline & B. Melsen & B. Wilmes & D. Chillès \\
\hline \multicolumn{4}{|l|}{$\begin{array}{c}\text { Radiographical } \\
\text { assessment }\end{array}$} \\
\hline Advantages & $\begin{array}{l}\text { - Easy to set up } \\
\text { - Can cover the entire arch }\end{array}$ & $\begin{array}{l}\text { - Easy to set up } \\
\text { - Autonomous system allowing asymmet- } \\
\text { rical molar movements without multiat- } \\
\text { tachment }\end{array}$ & $\begin{array}{l}\text { - No embedding } \\
\text { - No inflammation around the screws }\end{array}$ \\
\hline Disadvantages & $\begin{array}{l}\text { - Root proximity and noble elements } \\
\text { - Sprouting and possible burial }\end{array}$ & $\begin{array}{l}\text { - Unimaxillary device } \\
\text { - Custom-made connectors } \\
\text { - Cost }\end{array}$ & $\begin{array}{l}\text { - Incision needed } \\
\text { - Custom-made connectors }\end{array}$ \\
\hline
\end{tabular}



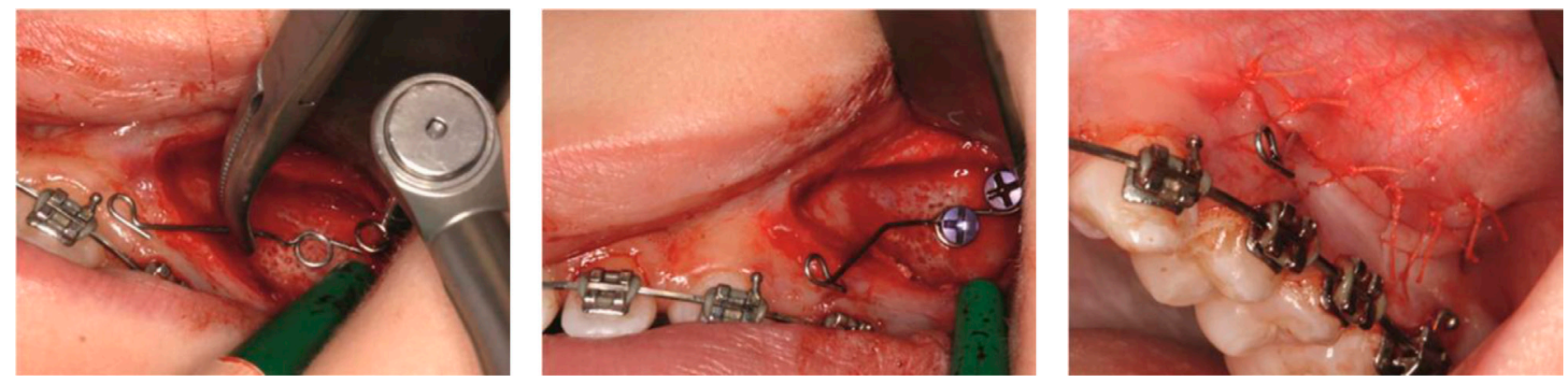

Figure 4

Insertion of subperiosteal screws. A very thick flap was created, concomitant to whic the connection was made in steel. The two screws were inserted into the loops. The flap was replaced and sutured with a 3-0 suture material.

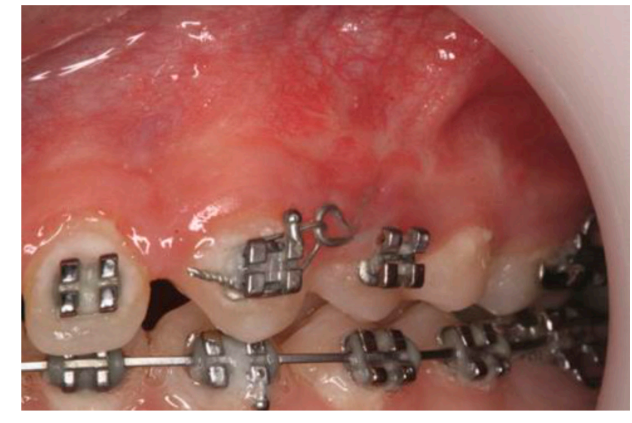

Figure 5

In the case of subperiosteal microscrews, the risk is the embedding of the connector, making it difficult to use and painful for patients. This is directly related to the patients' lack of hygiene.

from patients. These treatments are both orthodontic ${ }^{36}$ and orthopedic ${ }^{19}$.

However, unimaxillary bone anchor treatments do not facilitate a potentiating effect on mandibular growth in order to resolve class-II cases. It is, therefore, necessary to produce a detailed diagnosis and to define our objectives according to the extent to which a maxillary recoil and a mandibular advancement are desirable. The maxillary screws thus constitute an alternative, in the strictest sense, to the pendulum, distal jet, and other EOF devices used in the maxillary recoil, but they do not very often promote mandibular growth.

Although it is true that the patients' cooperation is no longer required because of the use of bone anchor screws, it is still necessary during the installation of the screws, a stage which can be tricky in children, adolescents, or even adults.

In addition, an impeccable hygiene regimen must be maintained by the patients throughout the treatment. If they fail to do this, they risk the manifestation of mucosal inflammation which will affect the smooth functioning of the mechanics and, in the worst case scenario, will compromise the stability of the screw.

\section{New perspectives}

The bone anchors continue to improve, opening the way to new orthodontic mechanics. From the transgingival screws described by Melsen, which are inserted into the alveolar bone, other devices and insertion sites have been developed (Table I).

This is the case for maxillary tuberosities. Screws $\leq 12 \mathrm{~mm}$ in length are implanted at a distance from the 

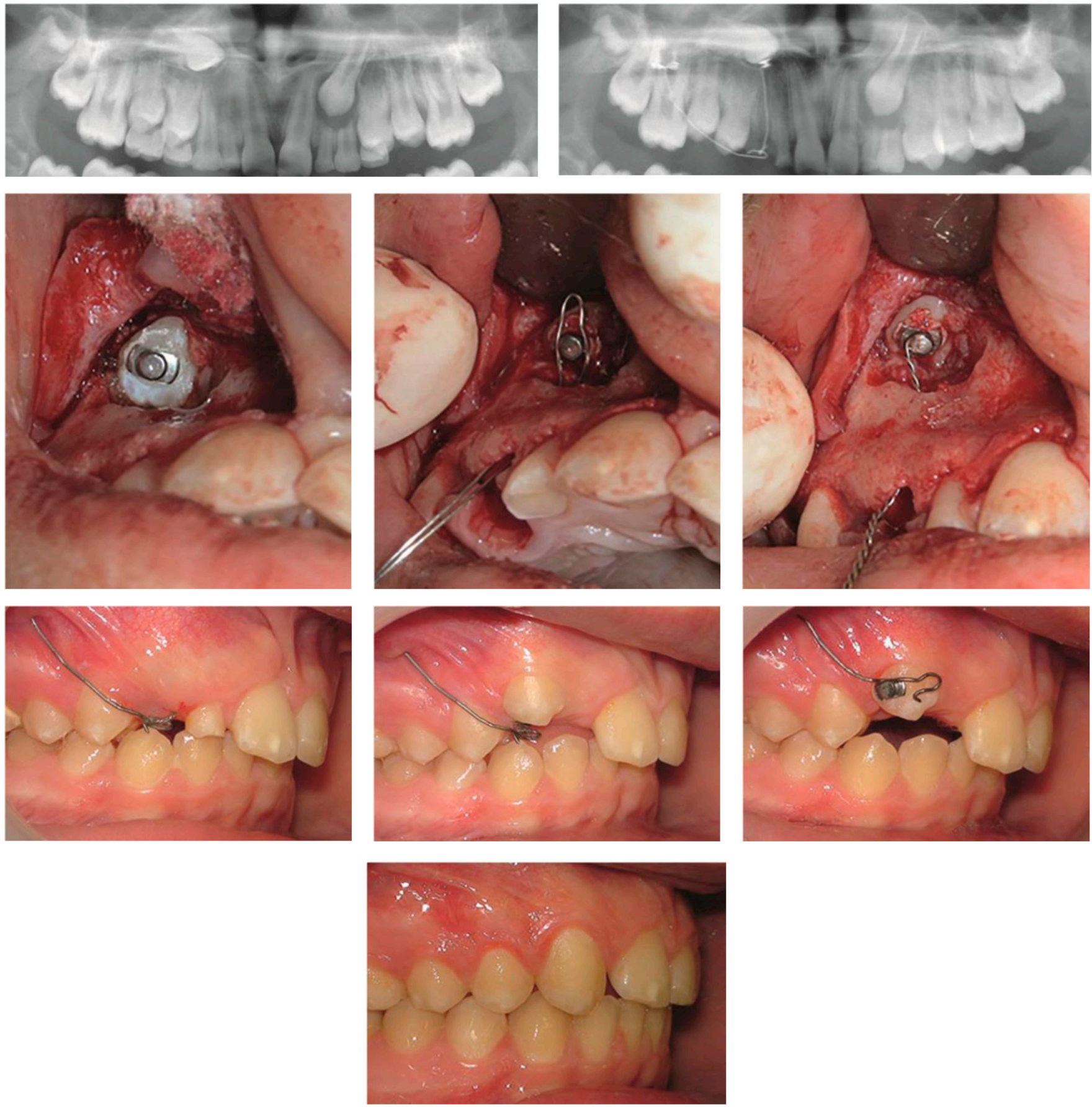

Figure 6

Case of placement of a canine retained vestibular in an 11-year-old patient. A flap is lifted to stick a button on the canine. This is connected by a metallic ligature to the active end of the "CT8-1" connector (Cortical-TMA-8-1-arm termination) fixed in the same session against the cortical bone of the zygomatic process by two embedded microscrews for a 3D control, and which emerges at the bottom of the vestibule at the molar level. (Courtesy of Dr. Daniel Chillès.) 
distal faces of the last molars. They serve as a direct anchorage for a progressive recoil of the maxillary arch.

They offer an alternative to traditional anchor plates. Although they require an incision line, it is easier to insert them. There are multiple areas of implantation. In the maxilla, they are mainly infrazygomatic and subnasal. At the mandibular level, there are the symphyseal regions, partly posterior to the crown and the retromolar trigon. The indications are vast: direct or indirect anchorage, anterior retraction, incisal or molar intrusion, adjustment of the molar axis, and insertion of canines retained among others (Fig. 6) ${ }^{9}$.

An implantation in the medial raphe area is also possible because it is anatomically safe. Wilmes has developed a set of connectors that can be supported by two palatine screws 11-mm and $9-\mathrm{mm}$ long by $2-\mathrm{mm}$ wide. The most anterior one is placed on the third palatal papilla, and the second is placed approximately $0.9 \mathrm{~mm}$ behind (Fig. 7). The steel connectors allow symmetrical or nonsymmetrical molar distalization and mesialization, with vertical dimension control26,50,52 (Fig. 8).

Other titanium alloy connectors can be used to position the retained canines or simply to intrude a sector. The advantage of these aids is to decrease the length of time spent wearing the multiattachment apparatus compared to other bone anchors, this allows both a better acceptance of the device and proportionally decreases the risk of problems like detachment, leucoma, or even gingivitis. This is only put in place after having established the desired molar ratios or after having engaged the canine on the arch. In addition, lingual or vestibular bonding, or even treatment with aligners, may be performed ${ }^{53,54,55}$ (Fig. 9).

However, this type of device encounters the same challenges as more conventional transgingival screws, i.e., the embedding of the screws (Fig. 10) or of the connectors (Fig. 9). The

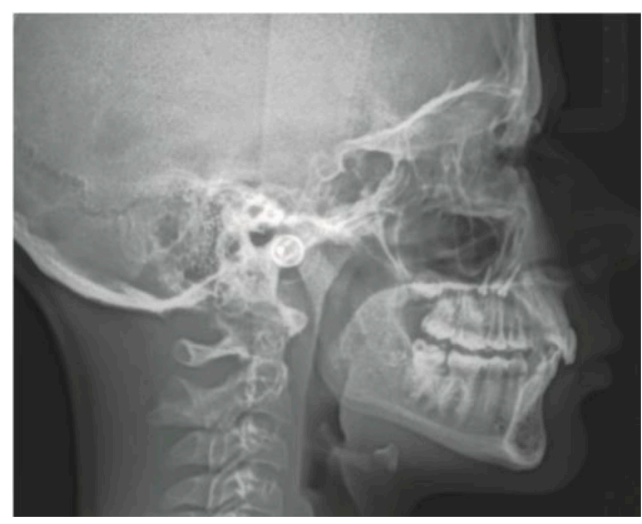

Figure 7

The Beneslider system is based on two screws implanted at the level of the medial raphe or on either side of the palatal suture. Note the proximity of the screws to the nasal cavity.

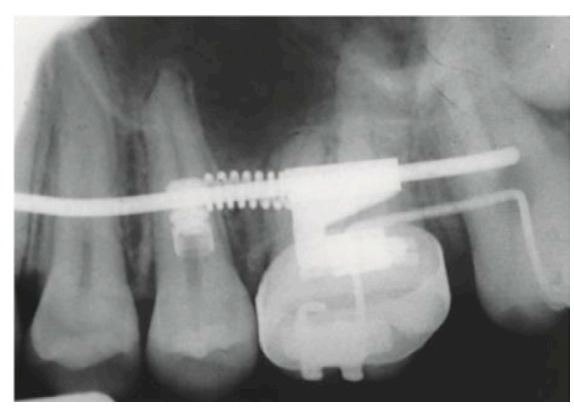

Figure 8

Wilmes device with its rigid connection allows a recoil intrusion of the molars.

Tipping is limited to the play of the tube surrounding the connector. Depending on the divergence of the connection with the occlusal plane, an intrusion or extrusion may be imposed on the molars. 

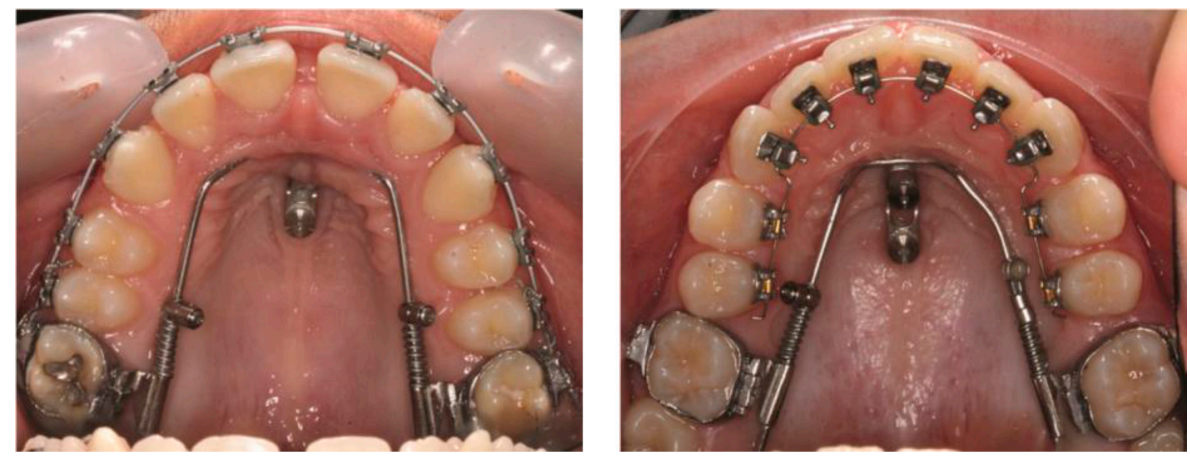

Figure 9

After establishing molar class-I ratios, the maxillary arch is glued. The Beneslider $®$ then constitutes a maximum anchorage on the molars. The multiattachment can be vestibular or lingual. Note the embedding of the device when the incisors are retracted.

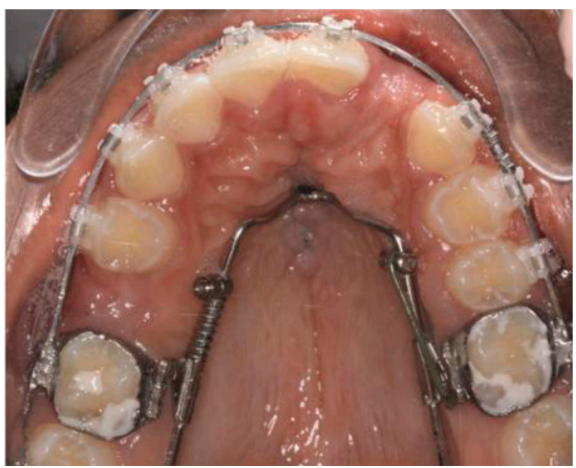

Figure 10

The central plate of the connector can be covered in case of insufficient hygiene.

Disinfection can only be conducted under local anesthesia.

depression of the anterior part of the connector may occur during anterior recoil in class-II treatment.

It is noteworthy that there are other devices that rest on the palatal screws ${ }^{47}$. In the end, they all have a dual purpose: facilitating the orthodontic mechanics by decreasing the need for patient participation but also limiting any undesirable effects. To achieve this, the practitioner must carefully analyze the system they set up and keep in mind that miniscrews do not remove all the confounding effects, as new mechanical constraints are produced.

\section{CONCLUSION}

Owing to the evolution of miniscrews over the past 20 years, as well as the experience gained by orthodontists, the use of these aids is becoming more and more frequent. However, pushing the limits of treatments in terms of the type and amplitude of movements begs two questions. The first concerns the safety of the treatments and their undesirable effects. For instance, can we assume that a $5-\mathrm{mm}$ molar recoil is feasible and poses no threat of radicular resorption under the pretext that it is assisted by bone anchors? The second question concerns the stability of the complex treatments facilitated by these anchorages. For example, will the closure of an anterior open bite 
be stable in the long-term without making any assumptions as to its etiology. The use of anchorage screws must always be well thought out and must under no circumstances be displaced by the rigorous control of the mechanical devices installed.

\section{ACKNOWLEDGMENTS}

The authors would like to thank Dr. Daniel Chillès for his contribution.

Conflict of interest: The authors have declared that they do not have any conflict of interest.

\section{BIBLIOGRAPHY}

1. Alsamak S, Bitsanis E, Makou M, Eliades G. Morphological and structural characteristics of orthodontic mini-implants. Morphol Strukt Merkmale Kieferorthopädischer Mini-Implant 2012;73(1):58-71.

2. Alsamak S, Psomiadis S, Gkantidis N. Positional guidelines for orthodontic mini-implant placement in the anterior alveolar region: a systematic review. Int J Oral Maxillofac Implants 2013;28(2):470-9.

3. Alves M, Baratieri C, Mattos CT, Araújo MT de S, Maia LC. Root repair after contact with mini-implants: systematic review of the literature. Eur J Orthod 2013;35(4):491-9.

4. Baumgaertel S. Hard and soft tissue considerations at mini-implant insertion sites. J Orthod 2014;41 Suppl 1:S3-7.

5. Bock NC, Ruf S. Skeletal anchorage for everybody? A questionnaire study on frequency of use and clinical indications in daily practice. J Orofac Orthop Fortschritte Kieferorthopädie OrganOfficial J Dtsch Ges Für Kieferorthopädie 2015;76(2):113-24, 126-8.

6. Bos A, Hoogstraten J, Prahl-Andersen B. The theory of reasoned action and patient compliance during orthodontic treatment. Community Dent Oral Epidemiol 2005;33(6):419-26.

7. Brisceno CE, Rossouw PE, Carrillo R, Spears R, Buschang PH. Healing of the roots and surrounding structures after intentional damage with miniscrew implants. Am J Orthod Dentofacial Orthop 2009;135(3):292-301.

8. ChenY, Kyung HM, Zhao WT, Yu WJ. Critical factors for the success of orthodontic miniimplants: A systematic review. Am J Orthod Dentofacial Orthop 2009;135(3):284-91.

9. Chillès $D$, Chillès $J-G$. Un dispositif à ancrage squelettique pour la traction et la mise en place des canines incluses. Rev Orthopédie Dento-Faciale 2009;43(1):6788.

10. Chillès J-G, Riemenschneider-Chillès $S$. [Use of short cortical mini-screws in orthodontics]. Orthod Fr 2011;82(3):253-68.

11. Clemmer EJ, Hayes EW. Patient cooperation in wearing orthodontic headgear. Am J Orthod 1979;75(5):517-24.

12. Consolaro A, Romano FL, Consolaro A, Romano FL. Reasons for mini-implants failure: choosing installation site should be valued! Dent Press J Orthod 2014;19(2):18-24.

13. Cope JB. Temporary anchorage devices in orthodontics: A paradigm shift. Semin Orthod 2005;11(1):3-9.

14. Costa A, Pasta G, Bergamaschi G. Intraoral hard and soft tissue depths for temporary anchorage devices. Semin Orthod 2005;11(1):10-5.

15. Costa A, Raffaini M, Melsen B. Miniscrews as orthodontic anchorage: a preliminary report. Int J Adult Orthodon Orthognath Surg 1997;13(3):201-9.

16. Dalstra M. Load transfer of miniscrews for orthodontic anchorage. Orthodontics 2004;1:53-62. 
17. Daniels AS, Seacat JD, Inglehart MR. Orthodontic treatment motivation and cooperation: A cross- sectional analysis of adolescent patients' and parents' responses. Am J Orthod Dentofacial Orthop 2009;136(6):780-7.

18. Dao V, Renjen R, Prasad HS, Rohrer MD, Maganzini AL, Kraut RA. Cementum, Pulp, Periodontal Ligament, and Bone Response After Direct Injury With Orthodontic Anchorage Screws: A Histomorphologic Study in an Animal Model. J Oral Maxillofac Surg 2009;67(11):24405.

19. De Clerck HJ, Cornelis MA, Cevidanes LH, Heymann GC, Tulloch CJF. Orthopedic Traction of the Maxilla With Miniplates: A New Perspective for Treatment of Midface Deficiency. J Oral Maxillofac Surg 2009;67(10):2123-9.

20. Hembree M, Buschang PH, Carrillo R, Spears R, Emile Rossouw P. Effects of intentional damage of the roots and surrounding structures with miniscrew implants. Am J Orthod Dentofacial Orthop 2009;135(3):280.e1-280.e9.

21. Hernández LC, Montoto G, Puente Rodríguez M, Galbán L, Martínez V. "Bone map" for a safe placement of miniscrews generated by computed tomography. Clin Oral Implants Res 2008;19(6):576-81.

22. Kadioglu O, Büyükyilmaz T, Zachrisson BU, Maino BG. Contact damage to root surfaces of premolars touching miniscrews during orthodontic treatment. Am J Orthod Dentofacial Orthop 2008;134(3):353-60.

23. Kim H, Kim T-W. Histologic evaluation of root-surface healing after root contact or approximation during placement of mini-implants. Am J Orthod Dentofacial Orthop 2011;139(6):752-60.

24. Kinzinger GSM, Eren M, Diedrich PR. Treatment effects of intraoral appliances with conventional anchorage designs for non-compliance maxillary molar distalization: a literature review. Eur J Orthod 2008;30(6):55871.

25. Lee K-J, Joo E, Kim K-D, Lee J-S, Park Y-C, Yu H-S. Computed tomographic analysis of tooth-bearing alveolar bone for orthodontic miniscrew placement. Am J Orthod Dentofacial Orthop 2009;135(4):486-94.

26. Ludwig B, Zachrisson BU, Rosa M. Non-compliance space closure in patients with missing lateral incisors. J Clin Orthod 2013;47(3):180-7.

27. Melsen B. Indications d'ancrage squelettique en orthodontie. Rev Orthopédie DentoFaciale 2006;40(1):4161.

28. Melsen B. Mini-implants: where are we? J Clin Orthod 2005;39(9):539.

29. Meursinge Reynders RA, Ronchi L, Ladu L, van EttenJamaludin F, Bipat S. Insertion torque and success of orthodontic mini-implants: A systematic review. Am J Orthod Dentofacial Orthop 2012;142(5):596-614.e5.

30. Migliorati $M$, et al. Miniscrew design and bone characteristics: an experimental study of primary stability. Am J Orthod Dentofacial Orthop 2012;142(2):228-34.

31. Migliorati $\mathrm{M}$, et al. Orthodontic miniscrews: an experimental campaign on primary stability and bone properties. Eur J Orthod 2015;37(5):531-8.

32. Monnerat C, Restle L, Mucha JN. Tomographic mapping of mandibular interradicular spaces for placement of orthodontic mini-implants. Am J Orthod Dentofacial Orthop 2009;135(4):428.e1-9; discussion 428-9.

33. Nanda RS, Kierl MJ. Prediction of cooperation in orthodontic treatment. Am J Orthod Dentofacial Orthop 1992;102(1):15-21.

34. Noorollahian S, Alavi S, Shirban F. Non-compliance Appliances for Upper Molar Distalization: An Overview. Int J Orthod Milwaukee Wis 2015;26(3):31-6.

35. Papadopoulos MA, Papageorgiou SN, Zogakis IP. Clinical effectiveness of orthodontic miniscrew implants: a meta-analysis. J Dent Res 2011;90(8):96976. 
36. Papadopoulos MA. Skeletal Anchorage in Orthodontic Treatment of Class II Malocclusion: Contemporary applications of orthodontic implants, miniscrew implants and mini plates. Elsevier Health Sciences, 2014; 309 p.

37. Papageorgiou SN, Zogakis IP, Papadopoulos MA. Failure rates and associated risk factors of orthodontic miniscrew implants: A meta-analysis. Am J Orthod Dentofacial Orthop 2012;142(5):577-95.e7.

38. Park H-S, Jeong S-H, Kwon O-W. Factors affecting the clinical success of screw implants used as orthodontic anchorage. Am J Orthod Dentofacial Orthop 2006;130(1):18-25.

39. Raji SH, Noorollahian S, Niknam SM. The effect of insertion angle on orthodontic miniscrew torque. Dent Res J 2014;11(4):448-51.

40. Renjen R, Maganzini AL, Rohrer MD, Prasad HS, Kraut RA. Root and pulp response after intentional injury from miniscrew placement. Am J Orthod Dentofacial Orthop 2009;136(5):708-14.

41. Samrit V, Kharbanda OP, Duggal R, Seith A, Malhotra V. Bone density and miniscrew stability in orthodontic patients. Aust Orthod J 2012;28(2):204-12.

42. Sarul M, Minch L, Park H-S, Antoszewska-Smith J. Effect of the length of orthodontic mini-screw implants on their long-term stability: a prospective study. Angle Orthod 2015;85(1):33-8.

43. Schätzle M, Männchen R, Zwahlen M, Lang NP. Survival and failure rates of orthodontic temporary anchorage devices: a systematic review. Clin Oral Implants Res 2009;20(12):1351-9.

44. Skidmore KJ, Brook KJ, Thomson WM, Harding WJ. Factors influencing treatment time in orthodontic patients. Am J Orthod Dentofacial Orthop 2006;129(2):230-8.

45. Son S, Motoyoshi M, Uchida Y, Shimizu N. Comparative study of the primary stability of self-drilling and self-tapping orthodontic miniscrews. Am J Orthod Dentofacial Orthop 2014;145(4):480-5.

46. Stockmann P, Schlegel KA, Srour S, Neukam FW, Fenner M, Felszeghy E. Which region of the median palate is a suitable location of temporary orthodontic anchorage devices? A histomorphometric study on human cadavers aged 15-20 years. Clin Oral Implants Res 2009;20(3):306-12.

47. Suzuki EY, Suzuki B. Maxillary molar distalization with the indirect Palatal miniscrew for Anchorage and Distalization Appliance (iPANDA). Orthod Art Pract Dentofac Enhanc 2013;14(1):e228-41.

48. Suzuki M, et al. Evaluation of optimal length and insertion torque for miniscrews. Am J Orthod Dentofacial Orthop 2013;144(2):251-9.

49. Tachibana R, Motoyoshi M, Shinohara A, Shigeeda T, Shimizu N. Safe placement techniques for self-drilling orthodontic mini-implants. Int J Oral Maxillofac Surg 2012;41(11):1439-44.

50. Wilmes B, Drescher D. Application and effectiveness of the Beneslider: a device to move molars distally. World J Orthod 2010;11(4):331-40.

51. Wilmes B, Drescher D. Impact of bone quality, implant type, and implantation site preparation on insertion torques of mini-implants used for orthodontic anchorage. Int J Oral Maxillofac Surg 2011;40(7):697-703.

52. Wilmes B, Katyal V, Willmann J, Stocker B, Drescher D. Mini-implant-anchored Mesialslider for simultaneous mesialisation and intrusion of upper molars in an anterior open bite case: a three-year follow-up. Aust Orthod J 2015;31(1):87-97.

53. Wilmes B, Neuschulz J, Safar M, Braumann B, Drescher D. Protocols for combining the Beneslider with lingual appliances in Class II treatment. J Clin Orthod 2014;48(12):744-52. 
54. Wilmes B, Nienkemper M, Ludwig B, Kau CH, Pauls A, Drescher D. Esthetic Class II treatment with the Beneslider and aligners. J Clin Orthod 2012;46(7):3908; quiz 437.

55. Wilmes B, Nienkemper M, Mazaud-Schmelter M, Renger S, Drescher D. [Combined use of Beneslider and lingual braces, mechanical aspects and procedures]. Orthod $\mathrm{Fr}$ 2013;84(4):347-59.

56. Wilson JJ, Harris EF. Compliance by state-subsidized and self-pay orthodontic patients. Am J Orthod Dentofacial Orthop 2015;148(4):628-32.

57. Zhang Y, Ni J, Smales RJ, Ma J, Wang L. Histologic investigation of gingival epithelium implantation and the nonincision placement of miniscrews. Int J Oral Maxillofac Implants 2014;29(5):1137-42.

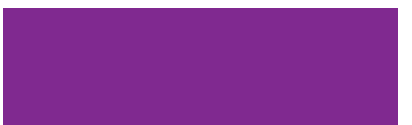

